
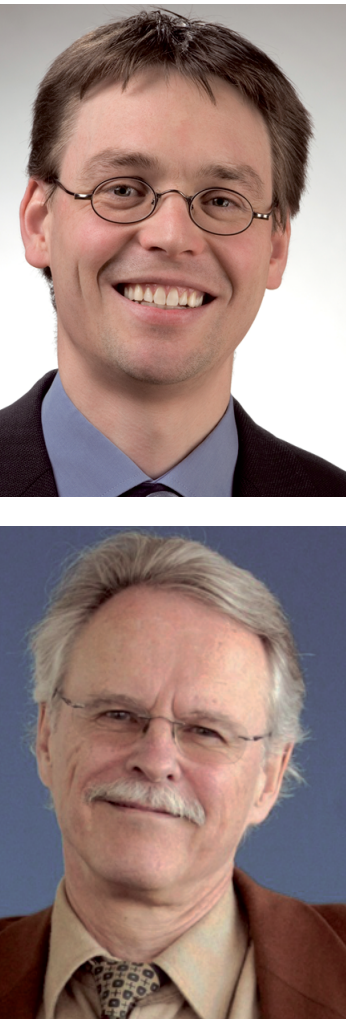

\section{HAPPINESS AND POLITICAL INSTITUTIONS}

\author{
Alois Stutzer* And
}

\author{
BRUNO S. FREY**
}

\section{What does happiness research mean for public policy?}

The study of individual happiness has enriched economics with many new and sometimes challenging (preliminary) insights. ${ }^{1}$ More and more often, it is asked about the policy consequences that are to be derived from these insights. We observe that economic research on happiness has an explicit or implicit tendency to follow a "benevolent dictator" approach where the government, and individual politicians and public officials, are assumed to be able and willing to pursue people's happiness, or to maximize a social welfare function where individuals' welfare is proxied by individuals' reported subjective well-being.

This article proposes a different approach by using the insights of public choice theory to develop the foundations of happiness policy. In particular, politicians are assumed to behave as other members of society do, and to be self-interested. However, they are subject to several constraints, in a democracy the need to secure reelection being the most important. Following the constitutional point of view (see, in particular, Buchanan and Tullock 1962; Brennan and Buchanan 1985) there are two levels at which policy decisions are taken: in the current politico-economic process within given rules, and at the constitutional level, where the rules of the game as such are determined.

The goal of our contribution is threefold. First, our discussion should make clear that the policy ap-

\footnotetext{
* Department of Business and Economics, University of Basel, email: alois.stutzer@unibas.ch.

** Institute for Empirical Research in Economics, University of ** Institute for Empirical Research

Both authors are also associated with CREMA - Center for

Research in Economics, Management and the Arts, Switzerland.

${ }^{1}$ See the first contribution in this forum for references.
}

proach matters for the choice of research questions and thus for the kind of knowledge happiness research aims to provide, as well as for the people seen as addressees. Second, we emphasize that there is no shortcut to an optimal happiness policy maximizing some aggregate happiness indicator as a social welfare function. Third, we argue instead that a constitutional perspective should be applied focusing on (political) institutions.

\section{Happiness optimal policy interventions}

The ordinalist revolution in economics, on which classical micro-economics is firmly based, takes it for granted that individual welfare can be measured only in an ordinal, but not in a cardinal way, and that it makes no sense to make interpersonal comparisons of utility. These are exactly the fundamental assumptions where the countermovement of happiness research sets in. Both cardinality and interpersonal comparability may be less of a problem on a practical level than on a theoretical level.

If the accumulated evidence is judged sufficient, in the sense that it allows for the cardinal measurement and interpersonal comparison of happiness, then it may be argued that one or more social welfare functions exist which can be used to derive policies to be pursued by democratic governments. One specific social welfare function is the unweighted sum of individual cardinal welfare or happiness. This function could be considered 'democratic' in the sense of attributing equal weight to each person. In contrast, the prices relevant for assessing the value of goods entering GNP are largely determined by the preferences of people with high purchasing power. The preferences of individuals without any income to spend are disregarded.

These steps towards aggregate happiness as a proxy measure for social welfare would fulfill an old dream in economics. It seems that the (so far empirically empty) social welfare maximum of the quantitative theory of economic policy has at long last been filled with life. Based on this - so the idea - a welfare max- 
imizing macro policy or optimal taxation policy (for a discussion see Weisbach 2008) and such like can be pursued.

However, we nevertheless argue in the following sections that, for a number of reasons, the presumed "socially optimal" values for the various determinants of happiness should not - and will not - be used as policy goals to be pursued by democratic governments. In order to avoid any misunderstandings, we certainly do not argue that GNP should be maximized instead of happiness. Rather, we favor a different approach in order to use the valuable insights gained from happiness research.

\section{Objections from political economics to the maximization of aggregate happiness}

The social welfare maximization approach disregards, and tries to substitute for, existing political institutions and processes. This is the "benevolent dictator" view castigated in constitutional political economy. It applies to all kinds of efforts to derive a "socially optimal" policy from the above, i.e., by maximizing an aggregate goal function. In a democracy, there are constitutionally designed rules and institutions allowing citizens to reveal their preferences and to provide politicians (the government) with an incentive to actualize them. As such, the maximization of a social welfare function is an intellectual exercise. Even if the government were to pay attention to the results, it has limited incentive to follow up on them.

\section{Citizens as metric stations}

The social welfare maximizing approach, based on empirically estimated happiness functions, disregards the institutions on which democracy is based. Citizens are reduced to 'metric stations'. They are forced into a state of passivity, which tends to increase their alienation from the state. In this respect, a happiness maximization approach is inimical to democracy. It disregards the interaction between citizens and politicians, the special-interest lobbying of organized groups and the concomitant information and learning processes.

The latter argument refers to the fundamental direct interrelation between the approach applied to collective choices in a society and individual well-being. People have preferences for processes over and above outcomes. They gain well-being from living and acting under institutionalized processes, as they contribute to a positive sense of self, addressing innate needs of autonomy, relatedness and competence. We call this contribution to individual well-being "procedural utility". In the economy, individuals have been shown to enjoy procedural utility in their capacities as consumers or income earners; in the polity and society, as citizens subjected to different political and societal procedures; in organizations, as employees confronted with different organizational procedures; and in law, as litigants (for an introductory survey, see Frey et al. 2004, and for an application to democracy, see Frey and Stutzer 2005). If people are reduced to "metric stations", they experience a significant loss of autonomy, and therefore reduced (procedural) well-being, when dealing with public affairs.

Happiness research also fails to provide a rule about the scope and limitations of government intervention in the private sphere. Should the government be allowed to prohibit the consumption of alcohol if this were to raise the population's happiness in the long run, or should this be left to the discretion of individuals (based on the results of happiness research)? And even more importantly: To what extent should the government be allowed to change the preferences of its citizens? Many current interventions might affect people's well-being in the future due to a change in preferences. Consider two extreme cases. Suppose that the government could adopt a policy of making people humble by reducing their material aspirations initially so that they are more appreciative of material benefits afterwards. Or, suppose that the government could raise a National Happiness Indicator by inducing people to take a "happiness pill". Should such policies be accepted? This question cannot be answered within the happiness maximization calculus, but must be decided at a more fundamental level. A feasible and theoretically consistent approach is to resort to the constitutional level, where people make such fundamental decisions behind the veil of uncertainty (see the section on a constitutional perspective below).

Probably the most fundamental issue is whether happiness is the ultimate goal to be maximized. Other valid goals, for instance, may be loyalty, responsibility, self-esteem, freedom or personal development. Whether happiness is the ultimate goal of individuals, or whether it is only one of several 
goals, has been a controversial issue in philosophy for centuries.

\section{Playing the system}

So far, we have assumed that the decision to maximize social welfare in terms of aggregate (measured) happiness does not have any influence on the measurement of subjective well-being. This assumption is highly debatable. Indeed, the political use of aggregate happiness would certainly induce strategic interactions between government and individuals. Two kinds of distortions need to be taken into account.

Once aggregate happiness has become politically relevant, the government, public bureaucracy and various interest groups have an incentive to manipulate it. This has proved to be true for GNP and for other economic indicators declared to be goals of government activity such as the unemployment rate, budget deficits and public debts. In the rare case that a government is unable to manipulate a particular indicator to its benefit, it has an incentive to create new indicators. This is easily possible in the case of happiness. A variety of indicators may capture individual well-being. Governments and pressure groups will choose those indicators most beneficial to their respective interests, or will create new ones better suited to their purposes.

A second systematic distortion stems from respondents' incentives to misrepresent their well-being. When individuals become aware that the happiness level they report influences the behavior of political actors, they have an incentive to misrepresent it. They can "play the system".

\section{Two limitations that ask for prudence}

\section{Consequences of adaptation and aspirations for public policy?}

A central finding in happiness research is that many effects of life circumstances have only a short-lived effect on reported subjective well-being. Extreme and well-known examples are paraplegics who after a time of hardship in the long run report to be only a little less happy than before, and lottery winners who after a short period of elation report to be not much happier than before. A more recent study based on longitudinal data finds that average life satisfaction drops when being subjected to a moderate disability but almost fully recovers to the pre-disability level after two years. In the case of a severe disability the recovery, however, is incomplete (Oswald and Powdthavee 2008).

The second, closely related phenomenon is the change of people's aspirations due to changes in their life circumstances. In the context of economics, an important finding is that people adjust to increases in their income (e.g. Stutzer 2004).

Hedonic adaptation and the aspiration treadmill are not problematic as such for the measurement of individual welfare. However, they have great consequences for social welfare maximization depending on how they are treated. Let us consider the case where courts have to decide about compensation for losses suffered in a car accident. For the same physical harm, should they award lower damages to people with a strong capacity to adapt and higher damages to others? Or in the area of government taxation, what costs of taxation should be taken into account? Materialists with high income aspirations suffer a great deal from personal income taxes. Should they be exempted from tax and government services be financed by people who can easily adapt to whatever material living standard they are confronted with?

What matters in our context is that the means for dealing with hedonic adaptation and the aspiration treadmill are not part of the formal happiness maximization. Instead the means must be sought at a more fundamental level, i.e., at a constitutional level. A social decision making mechanism is required to indicate how adaptation and aspiration effects have to be dealt with in public policy. Obviously such decisions have grave consequences for economic policy, which the social welfare maximization approach cannot address.

\section{Happiness measures as normative preferences}

The various happiness measures capture different aspects of individual well-being and thus different concepts of individual welfare. For a measure of reported subjective well-being to serve as a proxy for individual welfare, an important assumption is necessary: The standards underlying people's judgments are those the individual would like to pursue in realizing his or her ideal of the good life. People's judgments about their life can then serve as a proxy for their individual welfare. People are assumed to pursue individual welfare based on some stable evaluation 
standards. Moreover, the extent to which individual welfare is identified depends on whether the evaluation metric fits people's judgments about their life. The normative basis of this approach thus goes beyond assuming the pursuit of happiness and also involves choosing the concrete evaluation metric to elicit people's judgments.

Some people might favour a distant perspective reflecting on one's life ex post facto, while others favour the reasoned ex ante evaluations as their standards. Still others might give priority to how they feel when experiencing life as it occurs. Imagine those people who see happiness or high standards of individual welfare as a cognitive appraisal that the overall quality of life is judged in a favourable way. For them, general evaluations of their satisfaction with life as a whole might be an appropriate metric to capture judgments about individual welfare. For those people who equate individual welfare with momentto-moment affect, individual welfare might be best measured by such approaches as the experience sampling method or the day reconstruction method.

\section{A constitutional perspective on happiness research}

Based on the outlined objections and limitations, we argue that happiness research should not aim at constructing a social welfare function at all. Instead the insights provided by happiness research should be used in a different way. Our vision rests on the fundamental presumption that the quality of the political process is a key factor in people's happiness and that the legitimacy of political action finally rests on the voluntary agreement of the citizens involved. Individual sovereignty should not be reduced to selfreports on well-being. It should include choices on how to best pursue happiness, both individually and collectively. The claim is not for 'naïve' consumer or citizen sovereignty, which assumes optimal behavior. People, with their bounded rationality and bounded willpower, are sometimes aware of their own limitations (and sometimes aware only of the limitations of their fellow citizens).

Accordingly, at the collective level, the political process should be institutionally structured so that people's common interests become the principal driving force. Economic policy must help to establish those fundamental institutions, which make politicians and public bureaucrats most responsive to people's common interests (dominating behind a veil of uncertain- ty) and which finally lead to the best possible fulfillment of individual preferences. As argued above, happiness is not necessarily people's ultimate goal. It may even be that people see some virtue in unhappiness if they reckon that discontent is the only way to overcome social ills.

Happiness research has two different practical uses for policy: (1) It helps to identify which institutions enable individuals to best meet their preferences and which therefore contribute most to their personal happiness; (2) It provides important informational inputs for the political process.

(1) Happiness research provides insights on how, and to what extent, institutions have systematic effects on indicators of individual well-being. The emphasis is on institutions rather than specific policy interventions. To give an example, happiness policy should focus on the relationship between the fiscal constitution of a jurisdiction and people's subjective well-being rather than on the optimal tax scheme in terms of happiness. The range of institutions under study includes selfbinding mechanisms, social norms, private and public law (i.e., the rules of the game), as well as constitutional conditions on how to choose rules. The latter, for example, involves the possibility of direct democratic decision making (Frey and Stutzer 2000).

(2) The results gained from happiness research should be taken as informational inputs into the political process. These inputs have yet to prove themselves in political competition, in citizens' discourse, and also in the discourse between citizens and politicians. Happiness research already has produced many insights, which can be introduced into the political discussion process. They include policy issues like, for example, the effect of mandatory retirement and mandatory schooling on happiness (Charles 2004; Oreopoulos 2007); the impact of tobacco taxes on smokers' well-being (Gruber and Mullainathan 2005); or the relation between working time regulations and people's subjective well-being (Alesina et al. 2005). A competent overview of selected findings, with policy relevance, is provided by Diener et al. (2010).

The proposed constitutional vision takes into account that there is a demand for happiness research in the current politico-economic process. For example, parties in competition will want to learn about voters' preferences from data on reported subjective 
well-being. This demand for analyses might include evaluations of specific policy issues as well as grand policy schemes. Or, the public administration involved in valuing public goods will use the life satisfaction approach (for a review, see Frey et al. 2010) in order to get complementary information for cost-benefit analyses.

\section{Concluding remarks}

We asked at the outset about the consequences of happiness research for public policy. Based on a political-economic analysis, we respond that the appropriate approach is not to maximize aggregate happiness directly by seeking to improve outcomes through direct policy interventions. Rather, we see the role of happiness research as seeking to improve the nature of the political processes. Individuals should have more opportunity of advancing what constitutes their idea of the good life, both individually and collectively. They should be made aware that different issues require different measures and indicators of well-being. Happiness research should remain open to constructing a number of different indicators, reflecting well-being according to different aspects of life. Plurality is a necessary consequence of the procedural view outlined. This is in stark contrast to the maximization approach requiring one single objective. From a constitutional standpoint, we conclude that people are best served with comparative institutional analyses on subjective well-being.

\section{References}

Alesina, A., E. Glaeser and B. Sacerdote (2005), "Work and Leisure in the United States and Europe: Why So Different?", in M. Gertler and K. Rogoff, eds., NBER Macroeconomics Annual 2005, MIT Press, Cambridge, Mass., 1-64.

Brennan, G. and J. M. Buchanan (1985), The Reason of Rules: Constitutional Political Economy, Cambridge University Press, Cambridge, Mass.

Buchanan, J. M. and G. Tullock (1962), The Calculus of Consent. Logical Foundations of Constitutional Democracy, University of Michigan Press, Ann Arbor.

Charles, K. K. (2004), "Is Retirement Depressing? Labor Force Inactivity and Psychological Well-Being in Later Life", in S. W. Polachek, ed., Accounting for Worker Well-Being. Research in Labor Economics, vol. 23, Elsevier, Amsterdam, 269-99.

Diener, E., R. Lucas, U. Schimmack and J. Helliwell (2010), WellBeing for Public Policy, Oxford University Press, Oxford

Frey, B. S. and A. Stutzer (2000), "Happiness, Economy and Institutions", Economic Journal 110(466), 918-38.

Frey, B. S. and A. Stutzer (2005), "Beyond Outcomes: Measuring Procedural Utility”, Oxford Economic Papers 57, 90-111.

Frey, B. S., M. Benz and A. Stutzer (2004), "Introducing Procedural Utility: Not Only What, But Also How Matters", Journal of Institutional and Theoretical Economic 160(3),377-401.
Frey, B. S., S. Luechinger and A. Stutzer (2010), "The Life Satisfaction Approach to Environmental Valuation", Annual Review of Resource Economics 2,139-60.

Gruber, J. H. and S. Mullainathan (2005), "Do Cigarette Taxes Make Smokers Happier?", Advances in Economic Analysis and Policy 5 (1), 1-43.

Oreopoulos, P. (2007), "Do Dropouts Drop out Too Soon? Wealth, Health, and Happiness from Compulsory Schooling", Journal of Public Economics 91(11-12), 2213-29.

Oswald, A. J. and N. Powdthavee (2008), "Does Happiness Adapt? A Longitudinal Study of Disability with Implications for Economists and Judges", Journal of Public Economics 92(5-6), 1061-77.

Stutzer, A. (2004), "The Role of Income Aspirations in Individual Happiness", Journal of Economic Behavior and Organization 54(1), 89-109.

Weisbach, D. A. (2008), "What Does Happiness Research Tell Us About Taxation?”, Journal of Legal Studies 37(S2), S293-S324. 